UDC 622.276

Author: GREZINA Olga Anatolyevna, Senoir Lecturer at the Department of «Oil and Gas Field Exploration and Development», Branch of Ufa State Petroleum Technological University in Oktyabrsky; Devonskaya St., 54a, Oktyabrsky, Republic of Bashkortostan, Russian Federation, e-mail:vsh@of.ugntu.ru; ugntu.grezina@mail.ru

\title{
EFFICIENCY EVALUATION FOR NANOMATERIALS APPLIED IN WELL BOTTOM ZONE TREATMENT AFTER COMPLETION OF WELL CONSTRUCTION
}

\section{Extended AbSTRACT:}

Efficient development of low production wells is not possible without the bottom zone treatment, both during the well development phase when its construction is completed and in the process of flow rate reduction during the operation phase.

The efficiency evaluation for the new technology, including one in which nanomaterials are used, implies comparison of the actual level achieved after the new technology has been applied with the projected baseline level that might be achieved by the previously applied technique.

The paper presents geological and statistical modeling of the bottom zone acid-implosion treatment performed with the hydrochloric acid solution in combination with the shock-wave effect characterized by cyclic recurrence and dynamic mode. The analyzed results have been achieved in the low permeable carbonate reservoir of a very complex geological structure in oil operating facility. The nature and the extent of geological-technological parameters influence on the acidimplosion treatment results were determined by the multiple regression method, and the most influential parameters were selected; recommendations for boreholes selection and technological parameters of treatment were made. Models to forecast flow rate and oil production growth, reduction of fractional oil content in the well production, the acid-implosion impact duration were elaborated. The models can be used to evaluate efficiency of bottom zone treatment technologies after completion of well construction with nanomaterials application.

Key words: well construction, nanomaterials, acid-implosion treatment, hydrochloric acid, geological-statistical models, results prediction. 
MACHINE-READABLE INFORMATION ON CC-LICENSES (HTML-CODE) IN METADATA OF THE PAPER

$<$ a rel="license" href="http://creativecommons.org/licenses/by/4.0/"><img alt="Creative Commons License"

style="border-width:0" src="https://i.creativecommons.org/l/by/4.0/88x31.png" $/></ \mathrm{a}><$ br $/><$ span xmlns:dct="http://

purl.org/dc/terms/" href="http://purl.org/dc/dcmitype/Text" property="dct:title" rel="dct:type" $>$ Efficiency

evaluation for nanomaterials applied in well bottom zone treatment after completion of well construction $</$ span $>$ by $<$ a

xmlns:cc="http://creativecommons.org/ns\#" href="Nanotehnologii v stroitel'stve = Nanotechnologies in Construction.

2017, Vol. 9, no. 6, pp. 65-86. DOI: dx.doi.org/10.15828/2075-8545-2017-9-6-65-86." property="cc:attributionName"

rel="cc:attributionURL">Grezina O.A. $</ a>$ is licensed under a $<$ a rel="license" href="http://creativecommons.org/licenses/

by $/ 4.0 / ">$ Creative Commons Attribution 4.0 International License $</ \mathrm{a}>$. $<$ br $/>$ Based on a work at $<$ a xmlns:dct="http://

purl.org/dc/terms/" href=" http://nanobuild.ru/en_EN/nanobuild-6-2017/" rel="dct:source"> http://nanobuild.ru/

en_EN/nanobuild-6-2017/</a $>$. $<$ br $/>$ Permissions beyond the scope of this license may be available at $<$ a xmlns:cc="http://

creativecommons.org/ns\#" href="ugntu.grezina@mail.ru" rel="cc:morePermissions">ugntu.grezina@mail.ru</a>.

\section{References:}

1. Muslimov R.Kh. Sovremennye metody povysheniya nefteizvlecheniya: proektirovanie, optimizatsiya i otsenka effektivnosti [Modern methods of oil recovery increasing: design, optimization and performance evaluation]. Kazan': FEN, 2005. 688 p. (In Russian).

2. Yakupov R.F., Mukhametshin V.Sh. Voprosy effektivnosti razrabotki nizkoproduktivnykh karbonatnykh kollektorov na primere Turneyskogo yarusa Tuymazinskogo mestorozhdeniya [Problem of efficiency of low-productivity carbonate reservoir development on example of Turnaisian stage of Tuymazinskoye field]. Neftyanoe khozyaystvo = Oil industry, 2013. № 12. P. 106-110. (In Russian).

3. Ibragimov N.G., Musabirov M.Kh., Yartiev A.F. Opyt promyshlennoj realizacii importozameshchayushchih tekhnologij intensifikacii dobychi nefti v PAO «Tatneft'» [Tatneft's experience in commercialization of import-substituting well stimulation technologies]. Neftyanoe khozyaystvo = Oil industry, 2015. № 8 . P. 86-89. (In Russian).

4. Webb K.J., Black C.J.J., Tjetland G. A Laboratory Study Investigating Methods for Improving Oil Recovery in Carbonates. International Petroleum Technology Conference. Doha, Qatar, 2005. P. 1-6. DOI: doi.org/10.2523/IPTC-10506-MS.

5. Economides J.M., Nolte K.I. Reservoir stimulation. West Sussex, England: John Wiley and Sons, 2000. $856 \mathrm{p}$.

6. Mukhametshin V.V., Andreev V.E., Dubinsky G.S., Sultanov Sh.Kh., Akhmetov R.T. The Usage of Principles of System Geological-Technological Forecasting in the Justification of the Recovery Methods. SOCAR Proceedings, 2016. № 3. P. 46-51. DOI: dx.doi.org/10.5510/OGP20160300288. (In Russian). 
7. Kadyrov R.R., Nizaev R.Kh., Yartiev A.F., Mukhametshin V.V. Ogranichenie vodopritoka v gorizontal'nyh skvazhinah na mestorozhdeniyah s trudnoizvlekaemymi zapasami nefti [A novel water shut-off technique for horizontal wells at fields with hard-to-recover oil reserves]. Neftyanoe khozyaystvo = Oil industry, 2017. № 5 . P. 44-47. (In Russian).

8. Lungwitz B., Fredd C., Brady M., Miller M.,Ali S., Hughes K. Diversion and Cleanup Studies of Viscoelastic Surfactant-Based Self-Diverting Acid. SPE International Symposium and Exhibition on Formation Damage Control. Lafayette, Louisiana, 2004. P. 1-10. DOI: doi.org/10.2118/86504-MS.

9. Mukhametshin V.Sh. Zavisimost nefteizvlecheniya ot plotnosti setki skvazhin pri razrabotke nizkoproduktivnykh karbonatnykh zalezhey [Dependence of crude-oil recovery on the well spacing density during development of low-producing carbonate deposits]. Neftyanoe khozyaystvo = Oil industry, 1989. № 12. P. 26-29. (In Russian).

10. Mukhametshin V.Sh., Zeigman Yu.V., Andreev A.V. Rapid assessment of deposit production capacity for determination of nanotechnologies application efficiency and necessity to stimulate their development. Nanotehnologii v stroitel'stve = Nanotechnologies in Construction, 2017. Vol. 9, № 3. P. 20-34. DOI: dx.doi. org/10.15828/2075-8545-2017-9-3-20-34. (In Russian).

11. Xie X., Weiss W.W., Tong Z.J., Morrow N.R. Improved Oil Recovery from Carbonate Reservoirs by Chemical Stimulation. SPE Journal, 2005. Vol. 10, № 3. P. 1-10. DOI: doi.org/10.2118/89424-PA.

12. Mukhametshin V.V., Andreev V.E., Zeigman Yu.V., Kotenev Yu.A., Sultanov Sh.Kh. Snizhenie riskov prinyatiya nizkoeffektivnykh upravlyayushchikh resheniy pri ispolzovanii kislotnykh sostavov, predotvrashchayushchikh emulsioobrazovanie [Reducing risks of low-efficiency managerial decision-making when using acidization compositions preventing emulsification]. Geology, Geophysics and Development of Oil and Gas Fields, 2017. № 5. P. 36-42. (In Russian).

13. Mukhametshin V.V. O neobhodimosti i sozdanii edinogo kompleksnogo metoda geologo-promyslovogo analiza i obobshcheniya effektivnosti vozdeystviya na prizaboynuyu zonu plasta [The need for creation of a unified comprehensive method of geological and field analysis and integration of data on effective influence on the bottom-hole formation zone]. Neftyanoe khozyaystvo = Oil industry, 2017. № 4 . P. 80-84. (In Russian).

14. Zeigman Yu.V., Mukhametshin V.Sh., Khafizov A.R., Kharina S.B. Prospects of Application of Multi-Functional Well Killing Fluids in Carbonate Reservoirs. SOCAR 
Proceedings, 2016. № 3. P. 33-39. DOI: dx.doi.org/10.5510/OGP20160300286. (In Russian).

15. Akhmetov R.T., Andreev A.V., Mukhametshin V.V. Residual oil saturation and the displacement factor prediction methodology based on geophysical studies data to evaluate efficiency of nanotechnologies application. Nanotehnologii v stroitel'stve $=$ Nanotechnologies in Construction, 2017. Vol. 9, № 5. P. 116-133. DOI: dx.doi.org/10.15828/2075-8545-2017-9-5-116-133. (In Russian).

16. Ibragimov N.G., Musabirov M.Kh., Yartiev A.F. Effektivnost' kompleksa tekhnologij stimulyacii skvazhin v OAO «Tatneft" " [Effectiveness of well stimulation technologies package developed by Tatneft]. Neftyanoe khozyaystvo = Oil industry, 2014. № 7. P. 44-47. (In Russian).

17. Khayredinov N.Sh., Popov A.M., Mukhametshin V.Sh. Povyshenie effektivnosti zavodneniya nizkoproduktivnykh zalezhey nefti $\mathrm{v}$ karbonatnykh kollektorakh [Increasing the flooding efficiency of poor-producing oil deposits in carbonate]. Neftyanoe khozyaystvo = Oil industry, 1992. № 9. P. 18-20. (In Russian).

18. Zeigman Yu.V., Mukhametshin V.Sh., Sergeev V.V., Kinzyabaev F.S. Experimental study of viscosity properties of emulsion system with $\mathrm{SiO}_{2}$ nanoparticles. Nanotehnologii v stroitel'stve $=$ Nanotechnologies in Construction, 2017. Vol. 9, № 2. P. 16-38. DOI: dx.doi.org/10.15828/2075-8545-2017-9-2-16-38. (In Russian).

19. Andreev A.V., Mukhametshin V.Sh., KotenevYu.A. Deposit Productivity Forecast in Carbonate Reservoirs with Hard to Recover Reserves. SOCAR Proceedings, 2016. № 3. P. 40-45. DOI: dx.doi.org/10.5510/OGP20160300287. (In Russian).

20. Mukhametshin V.V. Ustranenie neopredelennostey pri reshenii zadach vozdeystviya na prizaboynuyu zonu skvazhin [Eliminating uncertainties in solving bottom hole zone stimulation tasks]. Bulletin of the Tomsk Polytechnic University. Geo Assets Engineering, 2017. Vol. 328, № 7. P. 40-50. (In Russian).

21. Poplygin V.V., Beloglazova E.A., Ivanova A.S. Analiz rezul'tatov provedeniya kislotnyh obrabotok v slozhnyh geologo-tekhnologicheskih usloviyah [Analysis of acid treatments in complex geological and technological conditions]. Bulletin of PNRPU. Geology. Oil \& Gas Engineering \& Mining, 2014. Vol. 13, № 10. P. 8390. (In Russian).

22. Zeigman Yu.V., Lysenkov A.V., Mukhametshin V.V., Sultanov Sh.Kh., Kotenev Yu.A. $\mathrm{K}$ voprosu vybora tekhnologii kislotnogo vozdejstviya dlya intensifikacii dobychi nefti [Some aspects of an acidizing technology choice to enhance oil production]. Geology, Geophysics and Development of Oil and Gas Fields, 2017. № 6. P. 44-50. (In Russian). 
23. Nikitin V.S., Glebov S.D., Sagitov D.K., Makhmutov A.A. Sovershenstvovanie metodov ocenki i planirovaniya geologo-tekhnicheskih meropriyatij na baze statisticheskih dannyh [Perfection of methods applied for planning of geologicaltechnical activities on the basis of statistical data]. Neftepromyslovoe delo, 2014. № 12. P. 26-29. (In Russian).

24. Patent no. 2117145 Russian Federation, MPK E 21 B 43/25.Sposob obrabotki prizabojnoj zony dobyvayushchej skvazhiny [Production well bottom hole formation zone treatment technique], Suleymanov E.I., Ganiev G.G., Ivanov A.I., Valeev M.Kh., Sivukhin A.A.; patentee and assignee OGPD «Bavlyneft» OSC «Tatneft» . No. 98103573/03. Declared 27.02.98. Published 10.08.98. Bulletin No. 22. 4 p. (In Russian).

25. Khannanov R.G., Shakirov R.M., Sivukhin A.A., Grezina O.A. Tekhnologiya kompleksnogo vozdejstviya na prizabojnuyu zonu plasta - prioritetnoe napravlenie razvitiya metodov stimulyacii slozhnopostroennyh karbonatnyh kollektorov $\mathrm{v}$ NGDU «Bavlyneft" " [Bottomhole formation zone complex treatment technology as a priority development direction for complex structure carbonate reservoirs stimulation techniques in OGPD «Bavlyneft»]. Georesursy, 2006. № 3. P. 15-17. (In Russian).

26. Grezina O.A. Kriterii ocenki rezul'tatov kislotno-implozionnogo vozdejstviya v neftyanyh skvazhinah [Acid-implosion evaluation criteria impact in oil wells]. Proceedings of International Scientific and Technical Conference «Modern Technologies in Oil and Gas Business - 2015»: in 2 volumes. Ufa: Arkaim, 2015. Vol. 1. P. 73-78. (In Russian).

27. Ivanov A.I., Khannanov R.G., Ismagilov O.Z., Grezina O.A. Osobennosti ekspluatacii gorizontal'nyh skvazhin v NGDU «Bavlyneft" [Horizontal wells operation peculiarities in OGPD «Bavlyneft»]. «Horizontal Wells: Drilling, Exploitation, Exploration seminar-discussion proceedings». Kazan’: Master Layn, 2000. P. 4854. (In Russian).

28. Kneller L.E., Gayfullin Ya.S., Antonov K.V. et al. Analiz vozmozhnostej ocenki potencial'nyh debitov gorizontal'nyh skvazhin na osnove modelirovaniya pritoka $\mathrm{s}$ ispol'zovaniem geologo-geofizicheskoj informacii [Horizontal wells potential production rates possibilities estimating analysis on the basis of inflow modeling with geological and geophysical information using]. «Horizontal Wells: Drilling, Exploitation, Exploration seminar-discussion proceedings». Kazan’: Master Layn, 2000. P. 172-180. (In Russian).

29. Gayfullin Ya.S., Kneller L.E., Grezina O.A. K ocenke vliyaniya osobennostej geologicheskogo razreza na potencial'nye debity gorizontal'noj skvazhiny [On the 
geological cross section peculiarities impact assessment on the horizontal well potential flow rates]. Geology, Geophysics and Development of Oil and Gas Fields, 2000. № 9. P. 29-35. (In Russian).

30. Patent no. 2117151 Russian Federation, MPK E 21 B 43/25.Sposob obrabotki prizabojnoj zony dobyvayushchej skvazhiny [Production well bottom hole formation zone treatment technique], Ibragimov N.G., Zalyatov M.M., Alenkin A.G., Valeev M.Kh.; patentee and assignee OSC «Tatneft» named after V.D. Shashin. No. 2013143187/03. Declared 24.09.13. Published 27.08.14. Bulletin No. 24. 5 p. (In Russian).

DeAR Colleagues!

THE REFERENCE TO THIS PAPER HAS THE FOLLOWING CITATION FORMAT:

Grezina O.A. Efficiency evaluation for nanomaterials applied in well bottom zone treatment after completion of well construction. Nanotehnologii $\mathrm{v}$ stroitel'stve $=$ Nanotechnologies in Construction. 2017, Vol. 9, no. 6, pp. 65-86. DOI: dx.doi. org/10.15828/2075-8545-2017-9-6-65-86. (In Russian). 
Автор: ГРЕЗИНА Ольга Анатольевна, старший преподаватель каф. «Разведка и разработка нефтяных и газовых месторождений», филиал Федерального государственного бюджетного образовательного учреждения высшего образования «Уфимский государственный нефтяной технический университет»; ул. Девонская, 54a, г. Октябрьский, Республика Башкортостан, Россия, 452607, e-mail: vsh@of.ugntu.ru; ugntu.grezina@mail.ru

\section{ОЦЕНКА ЭФФЕКТИВНОСТИ ИСПОЛЬЗОВАНИЯ НАНОМАТЕРИАЛОВ ПРИ ПРОВЕДЕНИИ ВОЗДЕЙСТВИЯ НА ПРИЗАБОЙНУЮ ЗОНУ СКВАЖИН ПОСЛЕ ЗАВЕРШЕНИЯ ИХ СТРОИТЕЛЬСТВА}

\section{АННОТАЦИЯ К СТАТЬЕ (АВТОРСКОЕ РЕЗЮме, РЕФЕРАТ):}

Эффективная разработка низкопродуктивных объектов невозможна без использования мероприятий по воздействию на призабойную зону скважин как на этапе освоения после завершения строительства, так и в процессе снижения дебита при эксплуатации.

Оценка эффективности новой технологии, в том числе с использованием наноматериалов, предполагает сравнение фактического уровня, достигнутого после применения новой технологии, с прогнозным базовым уровнем, который может быть обеспечен применявшимся ранее способом.

Выполнено геолого-статистическое моделирование результатов кислотно-имплозионного воздействия на призабойную зону скважин, осуществляемого с использованием солянокислотного раствора в сочетании с ударно-волновым воздействием, отличающееся цикличностью и динамическим режимом. Рассмотренные результаты достигнуты в скважинах нефтяного эксплуатационного объекта со слабопроницаемыми карбонатными коллекторами очень сложного геологического строения. Методом множественной регрессии определены характер и степень влияния геолого-технологических параметров на результаты кислотно-имплозионного воздействия, выбраны наиболее влияющие параметры; даны рекомендации по выбору скважин и технологических параметров воздействия. Построены модели для прогноза прироста дебита и добычи нефти, снижения доли нефти в продукции скважин, продолжительности эффекта кислотно-имплозионного воздействия, 
которые могут быть использованы при оценке эффективности технологий воздействия на призабойную зону скважин после завершения их строительства с использованием наноматериалов.

Ключевые слова: строительство скважин, наноматериалы, кислотноимплозионное воздействие, соляная кислота, геолого-статистические модели, прогноз результатов.

DOI: dx.doi.org/10.15828/2075-8545-2017-9-6-65-86

МАШИНОЧИТАЕМАЯ ИНФОРМАЦИЯ О СС-ЛИЦЕНЗИИ В МЕТАДАННЫХ СТАТЬИ (HTML-КОД):

$<$ a rel="license" href="http://creativecommons.org/licenses/by/4.0/" ><img alt="Лицензия Creative Commons" style="border-width:0" src="https://i.creativecommons.org/l/by/4.0/88x31.png" $/></ \mathrm{a}><$ br $/>$ Произведение " $<$ span xmlns:dct="http://purl.org/dc/terms/" href="http://purl.org/dc/dcmitype/Text" property="dct:title" rel="dct:type" $>$ Оценка эффективности использования наноматериалов при проведении воздействия на призабойную зону скважин после завершения их строительства </span>» созданное автором по имени <a xmlns:cc="http://creativecommons.org/ns\#" href="Нанотехнологии в строительстве. - 2017. - Том 9, № 6. - C. 65-86. - DOI: dx.doi.org/10.15828/2075-8545-2017-9-6-6586." property="cc:attributionName" rel="cc:attributionURL" $>$ Грезина O.A. $</$ a $>$, публикуется на условиях $<$ a rel="license" href="http://creativecommons.org/licenses/by/4.0/">лицензии Creative Commons «Attribution» («Атрибуция») 4.0 Всемирная $</ \mathrm{a}>$. $<$ br / > Основано на произведении c $<$ a xmlns:dct="http://purl.org/dc/terms/" href="http://nanobuild.ru/ru_RU/ nanobuild-6-2017/" rel="dct:source">http://nanobuild.ru/ru_RU/nanobuild-6-2017/</a>.<br />Разрешения, выходящие за рамки данной лицензии, могут быть доступны на странице $<$ a xmlns:cc="http://creativecommons.org/ns\#" href="ugntu. grezina@mail.ru"rel="cc:morePermissions">ugntu.grezina@mail.ru</a>

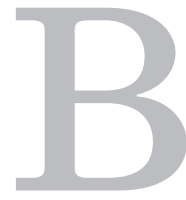

процессе завершения процесса строительства скважин для очистки и повышения продуктивности призабойной зоны широко используются различные методы воздействия на прискважинную зону пласта.

Одним из основных методов воздействия на призабойную зону скважин были и остаются воздействия с использованием соляно-кислотных растворов [1-6]. При этом используются различные технологии закачки в пласт кислотных растворов, которые различаются: объемами и давлениями закачки, использованием различных химических добавок, использованием композиций различных кислот, концентрацией соляной кислоты и т.д. [7-12].

Наличие широкого круга технологий объясняется необходимостью учета особенностей геологического строения объектов добычи нефти, стадий разработки месторождений и свойств пластовых флюидов [13-18]. 
Однако, как показывает опыт применения этого вида воздействия на призабойную зону, успешность проведения этих операций составляет менее $50 \%$, среди успешных воздействий около $30 \%$ являются нерентабельными, что является основанием для поиска новых технологий и обоснования их использования в условиях различных месторождений [19-22].

Среди наиболее перспективных и многообещающих методов находятся методы, основанные на использовании наноматериалов в тех или иных технологиях, в том числе и в технологиях, основанных по закачке солянокислотных растворов [18].

Однако при этом важным моментом является оценка эффективности технологий с применением нанодобавок по сравнению с технологиями без их использования, т.е. оценка чистого эффекта от использования наноматериалов. Такая оценка производится путем использования геолого-статистических моделей, построенных на основании обобщения опыта проведения воздействий на призабойную зону без использования нанодобавок. Сравнение значений эффекта (прогнозного по таким моделям) без использования нанодобавок и фактически полученных результатов с их использованием позволяет говорить об эффективности проведенных операций.

Модели для прогноза эффективности при использовании обычных солянокислотных обработок (СКО) и под давлением обстоятельно представлены в работах $[12,13,20,22]$, однако важно знать, как поведут себя наноматериалы в динамических процессах, в условиях резкого изменения давления в наносреде, которой является нефтесодержащая порода. При этом важно выбрать такую технологию, обобщить по ней геологопромысловый материал, построить модели и затем оценить «чистый» эффект с устранением посторонних «шумов».

Одной из таких технологий является кислотно-имплозионное воздействие (КИВ).

Для решения задачи построения оценочной модели было проведено обобщение опыта применения технологии увеличения дебита нефтяной скважины в результате комплексного воздействия на ее призабойную зону (ПЗС) в конкретных геолого-технологических условиях.

При этом были проведены:

- выбор показателей эффективности применения технологии и влияющих на них геолого-технологических параметров для анализа статистическим методом; 
- выбор скважин, определение значений геолого-технологических параметров и показателей эффективности;

- $\quad$ анализ характера и степени влияния геолого-технологических параметров на результаты применения технологии выбранным методом (для определения наиболее значимых параметров, совершенствования методики выбора скважин, распространения опыта на другие эксплуатационные объекты);

- построение статистических моделей для оценки прогнозных результатов применения технологии;

- составление выводов и рекомендаций по выбору скважин и технологических параметров воздействия.

Для исследования выбраны 50 операций по кислотно-имплозионному воздействию в скважинах турнейского яруса Бавлинского нефтяного месторождения. Для этого объекта средние геолого-физические параметры составляют: глубина кровли - 1240 м, эффективные нефтенасыщенная и водонасыщенная толщины - 5,78 и 7,11 м соответственно, коэффициент проницаемости - 0,012 мкм², средний коэффициент пористости - 0,11 единиц, вязкость нефти в пластовых условиях 20,8 мПа॰c.

Кислотно-имплозионное воздействие обеспечивает создание волновых колебаний, химическое воздействие и очистку ПЗС. Технология может применяться в вертикальных, наклонных и горизонтальных скважинах [23-25].

Первая скважино-операция для турнейского яруса выполнена в 1997 году. В период 1997-2010 гг. проведено более 300 обработок, в том числе не менее 100 обработок - в горизонтальных скважинах. Pезультаты воздействия периодически обобщались [26-28]. Базой сравнения являлась эффективность создания искусственных каверн-накопителей нефти (ИККН).

Технологическая схема воздействия в реальных скважинах изменялась во времени. Она должна была обеспечить предварительную очистку ПЗС от асфальтосмолопарафиновых отложений, динамический режим растворения породы, тщательную очистку ПЗС от продуктов реакции кислоты с породой.

Начальная технологическая схема включала:

- $\quad$ предварительную промывку скважины растворителем (без задавки его в ПЗС); 
- заполнение интервала продуктивного пласта солянокислотным раствором (без продавки его нефтью в ПЗС);

- технологическую выдержку для реакции кислоты с породой;

- вакуумно-импульсное воздействие с одновременной откачкой продуктов реакции и удалением из скважины части разрушившихся кольматирующих веществ (дренирование вакуумным насосом, свабирование вакуумным насосом, депрессионное воздействие, депрессионно-ударное воздействие, в конечном варианте - гидромеханическая обработка);

- $\quad$ повторение операций, при которых после каждого заполнения интервала продуктивного пласта солянокислотным раствором (без продавки его нефтью в ПЗС) объем порции раствора увеличивается в $1,15-1,25$ раза.

Технологические варианты:

- с заменой вакуумно-импульсного воздействия, например, после первых двух циклов закачки кислотного раствора, на промывку нефтью или свабирование;

- с изменением глубины спуска устройства для последующих циклов. Для обработки используется вакуумный насос (глубинный штанговый насос с заглушенной нижней частью и отверстиями в верхней части корпуса насоса). Эффект процесса имплозии обеспечивается последовательным возникновением вначале депрессии, а затем репрессии (гидравлического удара). Обеспечение как репрессивного (ударного), так и депрессивного воздействия определяется конструктивным исполнением устройства, предназначенного для создания эффекта имплозии [29].

Приняты следующие условия выбора скважино-операций:

- в скважинах с вертикальным и наклонно направленным профилем;

- без совмещения и наложения эффекта КИВ с эффектом других гео-

лого-технологических мероприятий (перфорацией, изменением типоразмера насоса и другими);

- $\quad$ с частичной продавкой растворителя в ПЗС и без таковой.

Статистические данные исследованы методом множественной регрессии.

Перечень независимых переменных (геолого-технологических параметров) $x_{i}$ включает: 1. Эфрективную нефтенасыщенную толщину пласта в скважине $H_{\text {э.н. }}$ м; 2. Среднюю толщину нефтенасыщенных 
пропластков в скважине $H_{\text {п }}$ м; 3. Количество нефтенасыщенных пропластков в скважине $n$, единиц; 4. Средневзвешенное значение коэффициента пористости пласта в скважине по данным ГИС $m, \%$; 5. Коэффициент нефтенасыщенности $K_{\text {н }}$, единиц; 6. Долю пород-коллекторов в общей толщине пласта $K_{\text {п }}$, единиц; 7. Расстояние до водоносного пласта $h_{\text {в }}$ м; 8. Время с начала эксплуатации скважины до момента проведения КИВ $t$, сут; 9. Максимальный дебит скважины до проведения КИВ $q_{\text {н } \max }$, т/сут; 10. Дебит скважины на момент проведения КИВ $q_{\text {н1 }}$, т/сут; 11. Обводненность продукции скважины на момент проведения КИВ $f_{1}, \% ; 12$. Накопленную добычу нефти на момент проведения КИВ $Q_{\text {н. }}$ нак т; 13. Текущее пластовое давление на момент проведения КИВ $P_{\text {пл }}^{\text {тек. }}$ $\mathrm{MПа;} \mathrm{14.} \mathrm{Относительное} \mathrm{снижение} \mathrm{пластового} \mathrm{давления} \mathrm{на} \mathrm{момент} \mathrm{про-}$ ведения КИВ (отношение текущего пластового давления к начальному) $P_{\text {пл }}^{\text {тек }} / P_{\text {пл }}^{\text {нач }} \% ; \mathbf{1 5}$. Объем растворителя АСПО (для очистки эксплуатационной колонны, без продавки в пласт) $V_{\text {р.Аспо }}^{\text {скв }}, \mathrm{M}^{3} ; \mathbf{1 6}$. Объем растворителя АСПО (для продавки в пласт) $V_{\text {р.Аспо }}$, м $^{3} ; \mathbf{1 7}$. Объем ингибированной соляной кислоты, $V_{\mathrm{k}}, \mathrm{M}^{3} ; \mathbf{1 8}$. Концентрацию ингибированной соляной кислоты $K, \% ; \mathbf{1 9}$. Количество циклов закачки кислоты, $n_{\text {ц.к. }}$, единиц; 20. Общее число двойных ходов плунжера устройства $n_{\text {д.х. }}$, единиц; 21. Количество операций свабирования $n_{\text {сваб }}$, единиц; 22. Кратность КИВ $N$, единиц.

Независимые переменные характеризуют геолого-физические свойства пластов, технологические особенности работы пласта и скважины, реализации воздействия.

В качестве зависимых переменных (показателей эффективности воздействия) $y_{i}$ выбраны: абсолютный $y_{1}$ (т/сут) и относительный $y_{2}(\%)$ начальные приросты дебита нефти, абсолютное $y_{3}(\%)$ и относительное $y_{4}(\%)$ снижение обводненности продукции, дополнительная добыча нефти $y_{5}=\Delta Q_{\text {н }}\left(\right.$ т) и продолжительность эффекта $y_{6}=T$ (сут).

Таблица 1

\begin{tabular}{|c|l|c|}
\hline $\boldsymbol{x}_{\boldsymbol{i}}$ & $\begin{array}{l}\text { Наиболее влияющие геолого-технологические параметры } \\
\text { на абсолютный прирост дебита нефти } \boldsymbol{y}_{1}\end{array}$ & Бета \\
\hline 2 & Средняя толщина нефтенасыщенных пропластков в скважине, м & $-0,673$ \\
\hline 3 & Количество нефтенасыщенных пропластков в скважине, единиц & $-0,541$ \\
\hline 16 & Объем растворителя АСПО (для продавки в пласт), м $^{3}$ & 0,514 \\
\hline
\end{tabular}


Окончание таб. 1

\begin{tabular}{|c|l|c|}
\hline 5 & Коэффициент нефтенасыщенности, единиц & 0,381 \\
\hline 10 & Дебит нефти для скважины на момент воздействия, т/сут & $-0,372$ \\
\hline 7 & Расстояние до водоносного пласта, м & 0,342 \\
\hline 1 & Эффективная нефтенасыщенная толщина пласта в скважине, м & 0,324 \\
\hline 11 & Обводненность продукции скважины на момент воздействия, \% & $-0,293$ \\
\hline 17 & Объем ингибированной соляной кислоты, м $^{3}$ & $-0,273$ \\
\hline
\end{tabular}

Таблица 2

\begin{tabular}{|c|l|c|}
\hline $\boldsymbol{x}_{\boldsymbol{i}}$ & \multicolumn{1}{|c|}{$\begin{array}{c}\text { Наиболее влияющие геолого-технологические параметры } \\
\text { на относительный прирост дебита нефти } \boldsymbol{y}_{2}\end{array}$} & Бета \\
\hline 10 & \multicolumn{1}{|c|}{ Дебит нефти для скважины на момент воздействия, т/сут } & $-0,669$ \\
\hline 5 & Коэффициент нефтенасыщенности, единиц & 0,513 \\
\hline 16 & Объем растворителя АСпО (для продавки в пласт), $\mathbf{m}^{3}$ & 0,406 \\
\hline 17 & Объем ингибированной соляной кислоты, м ${ }^{3}$ & $-0,293$ \\
\hline 2 & Средняя толщина нефтенасыщенных пропластков в скважине, м & $-0,287$ \\
\hline 1 & Эффективная нефтенасыщенная толщина пласта в скважине, м & 0,257 \\
\hline 3 & Количество нефтенасыщенных пропластков в скважине, единиц & $-0,243$ \\
\hline 7 & Расстояние до водоносного пласта, м & 0,228 \\
\hline 9 & Максимальный дебит нефти для скважины до воздействия, т/сут & $-0,221$ \\
\hline
\end{tabular}

Таблица 3

\begin{tabular}{|c|l|c|}
\hline $\boldsymbol{x}_{\boldsymbol{i}}$ & $\begin{array}{c}\text { Наиболее влияющие геолого-технологические параметры } \\
\text { на абсолютное снижение обводненности продукции } \boldsymbol{y}_{3}=\boldsymbol{f}_{1}-\boldsymbol{f}_{2}\end{array}$ & Бета \\
\hline 11 & Обводненность продукции скважины на момент воздействия, \% & 0,755 \\
\hline 17 & Объем ингибированной соляной кислоты, ${ }^{3}$ & $-0,482$ \\
\hline 21 & Количество операций свабирования & 0,352 \\
\hline 2 & Средняя толщина нефтенасыщенных пропластков в скважине, м & $-0,267$ \\
\hline 19 & Количество циклов закачки кислоты, единиц & 0,248 \\
\hline 20 & Общее число двойных ходов плунжера устройства, единиц & 0,246 \\
\hline 5 & Коэффициент нефтенасыщенности, единиц & 0,240 \\
\hline 10 & Дебит нефти для скважины на момент воздействия, т/сут & $-0,201$ \\
\hline 3 & Количество нефтенасыщенных пропластков в скважине, единиц & $-0,189$ \\
\hline
\end{tabular}


Таблица 4

\begin{tabular}{|c|c|c|}
\hline $\boldsymbol{x}_{\boldsymbol{i}}$ & $\begin{array}{c}\text { Наиболее влияющие геолого-технологические параметры } \\
\text { на относительное снижение обводненности продукции } \\
y_{3}=\left(f_{1}-f_{2}\right) / f_{1}\end{array}$ & Бета \\
\hline 17 & Объем ингибированной соляной кислоты, м $^{3}$ & $-0,393$ \\
\hline 11 & Обводненность продукции скважины на момент воздействия, \% & 0,369 \\
\hline 21 & Количество операций свабирования & 0,298 \\
\hline 19 & Количество циклов закачки кислоты, единиц & 0,222 \\
\hline 18 & Концентрация ингибированной соляной кислоты, \% & $-0,220$ \\
\hline 20 & Общее число двойных ходов плунжера устройства, единиц & 0,215 \\
\hline 3 & Количество нефтенасыщенных пропластков в скважине, единиц & $-0,210$ \\
\hline 16 & Объем растворителя АСПО (для продавки в пласт), м ${ }^{3}$ & 0,208 \\
\hline 7 & Расстояние до водоносного пласта, м & 0,182 \\
\hline
\end{tabular}

Таблица 5

\begin{tabular}{|c|l|c|}
\hline $\boldsymbol{x}_{i}$ & \multicolumn{1}{|c|}{$\begin{array}{c}\text { Наиболее влияющие геолого-технологические параметры } \\
\text { на дополнительную добычу нефти } \boldsymbol{y}_{5}\end{array}$} & Бета \\
\hline 3 & \multicolumn{1}{|c}{ Количество нефтенасыщенных пропластков в скважине, единиц } & $-0,572$ \\
\hline 10 & Дебит нефти для скважины на момент воздействия, т/сут & $-0,511$ \\
\hline 17 & Объем ингибированной соляной кислоты, ${ }^{3}$ & $-0,506$ \\
\hline 2 & Средняя толщина нефтенасыщенных пропластков в скважине, м & $-0,505$ \\
\hline 15 & $\begin{array}{l}\text { Объем растворителя АСПО (для очистки эксплуатационной } \\
\text { колонны, без продавки в пласт), м }{ }^{3}\end{array}$ & 0,494 \\
\hline 19 & Количество циклов закачки кислоты, единиц & 0,429 \\
\hline 11 & Обводненность продукции скважины на момент воздействия, \% & $-0,418$ \\
\hline 8 & $\begin{array}{l}\text { Время с начала эксплуатации скважины до момента } \\
\text { воздействия, сут }\end{array}$ & $-0,304$ \\
\hline 22 & Кратность воздействия, единиц & 0,295 \\
\hline
\end{tabular}

Таблица 6

\begin{tabular}{|c|l|c|}
\hline $\boldsymbol{x}_{\boldsymbol{i}}$ & $\begin{array}{c}\text { Наиболее влияющие геолого-технологические параметры на } \\
\text { продолжительность эффекта } \boldsymbol{y}_{\boldsymbol{b}}\end{array}$ & Бета \\
\hline 2 & Средняя толщина нефтенасыщенных пропластков в скважине, м & $-0,502$ \\
\hline 15 & $\begin{array}{l}\text { Объем растворителя АСПО (для очистки эксплуатационной } \\
\text { колонны, без продавки в пласт), } \mathrm{M}^{3}\end{array}$ & 0,487 \\
\hline
\end{tabular}


Окончание таб. 6

\begin{tabular}{|c|l|c|}
\hline 11 & Обводненность продукции скважины на момент воздействия, \% & $-0,460$ \\
\hline 13 & Текущее пластовое давление на момент воздействия, МПа & 0,316 \\
\hline 3 & Количество нефтенасыщенных пропластков в скважине, единиц & $-0,311$ \\
\hline 10 & Дебит нефти для скважины на момент воздействия, т/сут & $-0,305$ \\
\hline 14 & $\begin{array}{l}\text { Относительное снижение пластового давления на момент } \\
\text { воздействия (отношение текущего пластового давления } \\
\text { к начальному), \% }\end{array}$ & $-0,300$ \\
\hline 17 & Объем ингибированной соляной кислоты, м $^{3}$ & $-0,300$ \\
\hline 22 & Кратность воздействия, единиц & 0,291 \\
\hline
\end{tabular}

Средние значения показателей эффективности для выбранных скважино-операций составляют: прирост дебита нефти - 1,6 т/сут, дополнительная добыча нефти - 1282 т, продолжительность эффекта - 1778 сут.

Наиболее значимые параметры статистической модели оцениваются по величине стандартизованных регрессионных коэффициентов (бета-коэффициентов) [30]. Результаты оценки для КИВ приведены в табл. 1-6, параметры размещены в порядке убывания коэффициентов по модулю. Статистически значимые параметры (приемлемая граница ошибки $p<0,05)$ :

1) для абсолютного начального прироста дебита нефти - только объем растворителя асфальтосмолистых отложений (АСПО, для продавки в призабойную зону пласта);

2) для относительного начального прироста дебита нефти:

- дебит нефти для скважины на момент воздействия,

- коэффициент нефтенасыщенности,

- объем растворителя АСПО (для продавки в призабойную зону пласта);

3) для абсолютного снижения обводненности продукции $y_{3}=f_{1}-f_{2}$ :

- обводненность продукции скважины на момент воздействия,

- количество операций свабирования;

4) для относительного снижения обводненности продукции $y_{4}=$ $\left(f_{1}-f_{2}\right) / f_{1}-$ нет статистически значимых параметров;

5) для общего прироста добычи нефти за время эффекта:

- дебит нефти для скважины на момент воздействия,

- объем растворителя АСПО (для очистки эксплуатационной колонны, без продавки в призабойную зону пласта), 
- обводненность продукции скважины на момент воздействия;

6) для продолжительности эффекта - только обводненность продукции скважины на момент воздействия.

Положительные значения стандартизованных регрессионных коэффициентов означают улучшение результата (повышение эффективности) воздействия (за исключением относительного снижения пластового давления на момент воздействия).

Если рассмотреть наиболее значимые независимые параметры, то результаты КИВ улучшаются с увеличением коэффициента нефтенасыщенности, объемов растворителя АСПО для очистки эксплуатационной колонны (без продавки в ПЗС) и для продавки в ПЗС, количества операций свабирования, а также с уменьшением дебита нефти для скважины на момент воздействия. Отмечается неоднозначный характер влияния обводненности продукции скважины на момент воздействия: с увеличением этого параметра в большей степени снижается обводненность жидкости в начале эффективного периода, но при этом уменьшается дополнительная добыча нефти, продолжительность эффекта.

Построены статистические модели для оценки прогнозных результатов (показателей эффективности) применения КИВ в заданных условиях, величина коэффициента корреляции $R$ для которых подтверждает наличие связи для изучаемых параметров:

$$
\begin{aligned}
& \mathrm{y}_{1}=\Delta \mathrm{q}_{\mathrm{H}}=\mathrm{q}_{\mathrm{H} 2}-\mathrm{q}_{\mathrm{H} 1}=3,141+0,2429 \mathrm{H}_{\text {э.н. }}-0,4922 \mathrm{H}_{\text {пा }}-0,7823 \mathrm{n}-0,1538 \mathrm{~m}+ \\
& +0,05007 \mathrm{~K}_{\text {н }}+0,2380 \mathrm{~K}_{\text {п }}+0,03964 \mathrm{~h}_{\text {в }}-0,000137 \mathrm{t}-0,1079 \mathrm{q}_{\text {н } \max }- \\
& -0,5095 \mathrm{q}_{\text {н1 }}-0,02243 \mathrm{f}_{1}-0,000001 \mathrm{Q}_{\text {н.нак }}+0,08312 \mathrm{P}_{\text {пл }}^{\text {тек }}-
\end{aligned}
$$

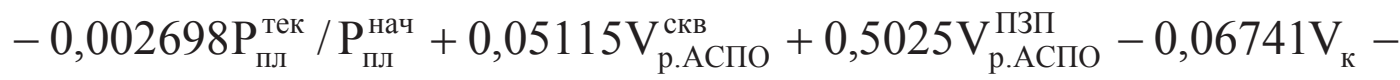

$$
\begin{aligned}
& -0,0325 \mathrm{~K}+0,1372 \mathrm{n}_{\text {ц.к. }}-0,000494 \mathrm{n}_{\text {д.х. }}+0,223 \mathrm{n}_{\text {сваб }}+0,5062 \mathrm{~N}(\mathrm{R}=0,734) \text {, } \\
& \mathrm{y}_{2}=\Delta \mathrm{q}_{\mathrm{H}} / \mathrm{q}_{\mathrm{H} 1}=\left(\mathrm{q}_{\mathrm{H} 2}-\mathrm{q}_{\mathrm{H} 1}\right) / \mathrm{q}_{\mathrm{H} 1}=-112,5+22,55 \mathrm{H}_{\text {э.н. }}-24,58 \mathrm{H}_{\text {п }}-41,19 \mathrm{n}- \\
& -3,224 \mathrm{~m}+7,895 \mathrm{~K}_{\mathrm{H}}-59,34 \mathrm{~K}_{\text {п }}+3,086 \mathrm{~h}_{\text {в }}-0,015 \mathrm{t}-21,01 \mathrm{q}_{\text {н } \max }- \\
& -107,44 \mathrm{q}_{\text {н1 }}-1,029 \mathrm{f}_{1}-0,000 \mathrm{Q}_{\text {н.нак }}+15,91 \mathrm{P}_{\text {пл }}^{\text {тек }}-0,156 \mathrm{P}_{\text {пл }}^{\text {тек }} / \mathrm{P}_{\text {пл }}^{\text {нач }}+ \\
& +3,713 \mathrm{~V}_{\text {р.АСПО }}^{\text {скв }}+46,508 \mathrm{~V}_{\text {р.АСПО }}^{\text {ПЗП }}-8,453 \mathrm{~V}_{\mathrm{\kappa}}-1,969 \mathrm{~K}+24,006 \mathrm{n}_{\text {ц.к. }}- \\
& -0,049 \mathrm{n}_{\text {д.х. }}+24,19 \mathrm{n}_{\text {сваб }}+45,29 \mathrm{~N}(\mathrm{R}=0,831),
\end{aligned}
$$


$\mathrm{y}_{3}=\Delta \mathrm{f}=\mathrm{f}_{1}-\mathrm{f}_{2}=-3,185+0,8960 \mathrm{H}_{\text {э.н. }}-1,336 \mathrm{H}_{\text {п }}-1,868 \mathrm{n}-0,0990 \mathrm{~m}+$ $+0,2162 \mathrm{~K}_{\text {н }}-6,105 \mathrm{~K}_{\text {п }}+0,1281 \mathrm{~h}_{\text {в }}-0,00016 \mathrm{t}-0,8864 \mathrm{q}_{\text {н } \max }-1,889 \mathrm{q}_{\mathrm{H} 1}+$ $+0,3957 \mathrm{f}_{1}-0,00001 \mathrm{Q}_{\text {н.нак }}+0,2416 \mathrm{P}_{\text {пл }}^{\text {тек }}+0,00239 \mathrm{P}_{\text {пл }}^{\text {тек }} / \mathrm{P}_{\text {пл }}^{\text {нач }}+$ $+0,05704 \mathrm{~V}_{\text {р.АСПО }}^{\text {скв }}+0,4687 \mathrm{~V}_{\text {р.АСПО }}^{\text {ПП }}-0,8141 \mathrm{~V}_{\text {к }}-0,5247 \mathrm{~K}+2,880 \mathrm{n}_{\text {ц.к. }}+$ $+0,00723 \mathrm{n}_{\text {д.х. }}+5,241 \mathrm{n}_{\text {сваб }}-1,048 \mathrm{~N}(\mathrm{R}=0,852)$,

$\mathrm{y}_{4}=\Delta \mathrm{f} / \mathrm{f}_{1}=\left(\mathrm{f}_{1}-\mathrm{f}_{2}\right) / \mathrm{f}_{1}=22,95+3,674 \mathrm{H}_{\text {э.н. }}-3,552 \mathrm{H}_{\text {п }}-8,651 \mathrm{n}+1,150 \mathrm{~m}+$ $+0,4623 \mathrm{~K}_{\mathrm{H}}-36,55 \mathrm{~K}_{\text {п }}+0,5999 \mathrm{~h}_{\mathrm{B}}+0,0007 \mathrm{t}-3,348 \mathrm{q}_{\text {н } \max }-4,673 \mathrm{q}_{\mathrm{H} 1}+$ $+0,8043 \mathrm{f}_{1}-0,0001 \mathrm{Q}_{\text {н.нак }}-1,7198 \mathrm{P}_{\text {пл }}^{\text {тек }}-0,0306 \mathrm{P}_{\text {пл }}^{\text {тек }} / \mathrm{P}_{\text {пл }}^{\text {нач }}+0,2401 \mathrm{~V}_{\text {р.АСпо }}^{\text {скв }}+$ $+5,805 \mathrm{~V}_{\text {р.АСПО }}^{\text {ПП }}-2,768 \mathrm{~V}_{\text {к }}-2,734 \mathrm{~K}+10,73 \mathrm{n}_{\text {ц.к. }}+0,0263 \mathrm{n}_{\text {д.х. }}+18,5 \mathrm{n}_{\text {сваб }}+$ $+0,0892 \mathrm{~N}(\mathrm{R}=0,566)$,

$$
\begin{aligned}
& \mathrm{y}_{5}=\Delta \mathrm{Q}_{\mathrm{H}}=-1360,49+27,73 \mathrm{H}_{\text {э.н. }}-182,81 \mathrm{H}_{\text {п }}-409,2 \mathrm{n}+96,93 \mathrm{~m}+17,6 \mathrm{~K}_{\mathrm{H}}+ \\
& +374,41 \mathrm{~K}_{\text {п }}+5,63 \mathrm{~h}_{\text {в }}-0,1 \mathrm{t}-29,78 \mathrm{q}_{\text {н } \max }-347 \mathrm{q}_{\text {н1 }}-15,82 \mathrm{f}_{1}+0,00 \mathrm{Q}_{\text {н.нак }}+ \\
& +94,83 \mathrm{P}_{\text {пл }}^{\text {тек }}-0,98 \mathrm{P}_{\text {пл }}^{\text {тек }} / \mathrm{P}_{\text {пл }}^{\text {нач }}+109,96 \mathrm{~V}_{\text {р.АСПО }}^{\text {скв }}+31,91 \mathrm{~V}_{\text {р.АСПО }}^{\text {ПЗП }}-61,74 \mathrm{~V}_{\text {к }}+ \\
& +21,99 \mathrm{~K}+359,5 \mathrm{n}_{\text {ц.к. }}-0,303 \mathrm{n}_{\text {д.х. }}+160,87 \mathrm{n}_{\text {сваб }}+342,6 \mathrm{~N}(\mathrm{R}=0,795) \text {, }
\end{aligned}
$$

$$
\begin{aligned}
& \mathrm{y}_{6}=\mathrm{T}=-3510,58-103,5 \mathrm{H}_{\text {э.н. }}-533,3 \mathrm{H}_{\text {п }}-652,1 \mathrm{n}+335,3 \mathrm{~m}+18,64 \mathrm{~K}_{\mathrm{H}}+ \\
& +2838,2 \mathrm{~K}_{\text {п }}+35,27 \mathrm{~h}_{\text {в }}-0,16 \mathrm{t}-307,1 \mathrm{q}_{\text {н max }}-608,4 \mathrm{q}_{\text {н1 }}-51,11 \mathrm{f}_{1}+0,02 \mathrm{Q}_{\text {н.нак }}+ \\
& +334,1 \mathrm{P}_{\text {пл }}^{\text {тек }}-7,5 \mathrm{P}_{\text {пл }}^{\text {тек }} / \mathrm{P}_{\text {пл }}^{\text {нач }}+317,8 \mathrm{~V}_{\text {р.АСПО }}^{\text {скв }}+311,4 \mathrm{~V}_{\text {р.АСПО }}^{\text {ПзП }}-107,3 \mathrm{~V}_{\text {к }}+ \\
& +89,7 \mathrm{~K}+143,7 \mathrm{n}_{\text {ц.к. }}-0,36 \mathrm{n}_{\text {д..х. }}+32,99 \mathrm{n}_{\text {сваб }}+993,13 \mathrm{~N}(\mathrm{R}=0,724) .
\end{aligned}
$$

Если рассмотреть все независимые параметры, то все результаты КИВ улучшаются:

- при увеличении эффективной нефтенасыщенной толщины пласта (кроме продолжительности эффекта), коэффициента нефтенасыщенности и расстояния до водонасыщенного интервала;

- при увеличении текущего пластового давления (кроме относительного снижения обводненности продукции), уменьшении степени 
снижения текущего пластового давления (кроме абсолютного снижения обводненности продукции);

- при увеличении объемов растворителя АСПО для очистки эксплуатационной колонны и закачки в ПЗС, количества циклов закачки кислоты, количества операций свабирования, кратности КИВ (кроме абсолютного снижения обводненности продукции). При этом результаты КИВ ухудшаются:

- при увеличении толщины нефтенасыщенных пропластков и их количества;

- при увеличении времени с начала эксплуатации скважины до момента воздействия (кроме относительного снижения обводненности продукции), максимального дебита скважины до воздействия, дебита скважины по нефти на момент воздействия;

- при увеличении концентрации кислоты.

Часть независимых параметров влияет на результаты КИВ неоднозначно:

- средневзвешенный коэффициент пористости пласта в скважине,

- доля пород-коллекторов в общей толщине пласта,

- обводненность жидкости на момент воздействия,

- накопленная добыча нефти на момент воздействия (слабое влияние),

- концентрация кислоты,

- общее число двойных ходов плунжера устройства (импульсов).

\section{Выводы}

1. Кислотно-имплозионное воздействие эффективно для низкодебитных скважин.

2. Статистическая оценка подтверждает практические предположения о целесообразности для кислотно-имплозионного воздействия предварительного удаления асфальтосмолопарафиновых отложений, цикличности закачки кислотного раствора, использования раствора небольших объема и концентрации, создания ограниченного количества импульсов, использования свабирования для удаления продуктов реакции, проведения повторных обработок.

3. Полученные статистические модели могут быть использованы для качественно-количественной оценки технологических результатов кислотно-имплозионного воздействия. 
4. Целесообразно продолжить исследование статистическими методами для обоснования использования воздействия в условиях других месторождений.

5. Проведенное исследование позволяет оценивать эффективность технологий воздействия на призабойную зону скважин после завершения их строительства с использованием наноматериалов.

\section{Библиографический список:}

1. Муслилов P.X. Современные методы повышения нефтеизвлечения: проектирование, оптимизация и оценка эффективности. - Казань: ФЭН, 2005. - 688 с.

2. Якупов Р.Ф. Вопросы эффективности разработки низкопродуктивных карбонатных коллекторов на примере турнейского яруса Туймазинского месторождения / Р.Ф. Якупов, В.Ш. Мухаметшин // Нефтяное хозяйство. - 2013. № 12. - C. 106-110.

3. Ибрагилов Н.Г. Опыт промышленной реализации импортозамещающих технологий интенсификации добычи нефти в ПАО «Татнефть» / Н.Г. Ибрагимов, М.Х. Мусабиров, А.Ф. Яртиев // Нефтяное хозяйство. - 2015. - № 8. - С. 86-89.

4. Webb K.J. A Laboratory Study Investigating Methods for Improving Oil Recovery in Carbonates / K.J. Webb, C.J.J. Black, G. Tjetland // International Petroleum Technology Conference. Doha, Qatar, 2005. P. 1-6. DOI: doi.org/10.2523/IPTC10506-MS.

5. Economides J.M. Reservoir stimulation / J.M. Economides, K.I. Nolte. - West Sussex, England: John Wiley and Sons, 2000. - 856 p.

6. The Usage of Principles of System Geological-Technological Forecasting in the Justification of the Recovery Methods / V.V. Mukhametshin, V.E. Andreev, G.S. Dubinsky, Sh.Kh. Sultanov, R.T. Akhmetov // SOCAR Proceedings, 2016. № 3. P. 46-51. DOI: dx.doi.org/10.5510/OGP20160300288.

7. Ограничение водопритока в горизонтальных скважинах на месторождениях с трудноизвлекаемыми запасами нефти / Р.Р. Кадыров, Р.Х. Низаев, А.Ф. Яртиев, В.В. Мухаметшин // Нефтяное хозяйство. - 2017. - № 5. - С. 44-47.

8. Diversion and Cleanup Studies of Viscoelastic Surfactant-Based Self-Diverting Acid / B. Lungwitz, C. Fredd, M. Brady, M. Miller, S. Ali, K. Hughes // SPE International Symposium and Exhibition on Formation Damage Control. Lafayette, Louisiana, 2004. P. 1-10. DOI: doi.org/10.2118/86504-MS. 
9. Мухалетшин В.Ш. Зависимость нефтеизвлечения от плотности сетки скважин при разработке низкопродуктивных карбонатных залежей // Нефтяное хозяйство. -1989 . - № 12. - С. 26-29.

10. Мухалетшин В.Ш., Зейглан Ю.В., Андреев А.В. Экспресс-оценка потенциала добывных возможностей залежей для определения эффективности применения нанотехнологий и необходимости стимулирования ввода их в разработку / / Нанотехнологии в строительстве. - 2017. - Том 9, № 3. - C. 20-34. - DOI: dx.doi.org/10.15828/2075-8545-2017-9-3-20-34.

11. Improved Oil Recovery from Carbonate Reservoirs by Chemical Stimulation / X. Xie, W.W. Weiss, Z.J. Tong, N.R. Morrow // SPE Journal, 2005. Vol. 10, № 3. P. 1-10. DOI: doi.org/10.2118/89424-PA.

12. Снижение рисков принятия низкоэффективных управляющих решений при использовании кислотных составов, предотвращающих эмульсиообразование / В.В. Мухаметшин, В.Е. Андреев, Ю.В. Зейгман, Ю.А. Котенев, Ш.Х. Султанов // Геология, геофизика и разработка нефтяных и газовых месторождений. - 2017. - № 5. - С. 36-42.

13. Мухалетшин B.В. О необходимости и создании единого комплексного метода геолого-промыслового анализа и обобщения эффективности воздействия на призабойную зону пласта // Нефтяное хозяйство. - 2017. - № 4. - С. 8084.

14. Prospects of Application of Multi-Functional Well Killing Fluids in Carbonate Reservoirs / Yu.V. Zeigman, V.Sh. Mukhametshin, A.R. Khafizov, S.B. Kharina // SOCAR Proceedings, 2016. № 3. P. 33-39. DOI: dx.doi.org/10.5510/ OGP20160300286.

15. Ахлетов P.T., Андреев А.В., Мухалетшин В.В. Методика прогноза остаточной нефтенасыщенности и коэффициента вытеснения по данным геофизических исследований для оценки эффективности применения нанотехнологий // Нанотехнологии в строительстве. - 2017. - Том 9, № 5. - С. 116- 133. - DOI: dx.doi.org/10.15828/2075-8545-2017-9-5-116-133.

16. Ибрагилов Н.Г. Эффективность комплекса технологий стимуляции скважин в ОАО «Татнефть» / Н.Г. Ибрагимов, М.Х. Мусабиров, А.Ф. Яртиев // Нефтяное хозяйство. -2014 . - № 7. - С. 44-47.

17. Хайрединов Н.Ш. Повышение эффективности заводнения низкопродуктивных залежей нефти в карбонатных коллекторах / Н.Ш. Хайрединов, А.М. Попов, В.Ш. Мухаметшин // Нефтяное хозяйство. - 1992. - № 9. - С. 18-20.

18. Зейглан Ю.В., Мухалетшин В.Ш., Сергеев В.В., Кинзябаев Ф.С. Экспериментальное исследование вязкостных свойств эмульсионных систем с содержани- 
ем наночастиц $\mathrm{SiO}_{2} / /$ Нанотехнологии в строительстве. - 2017. - Том 9, № 2. C. 16-38. - DOI: dx.doi.org/10.15828/2075-8545-2017-9-2-16-38.

19. Andreev A.V. Deposit Productivity Forecast in Carbonate Reservoirs with Hard to Recover Reserves / A.V. Andreev, V.Sh. Mukhametshin, Yu.A. Kotenev // SOCAR Proceedings, 2016. № 3. P. 40-45. DOI: dx.doi.org/10.5510/ OGP20160300287.

20. Мухалетшин В.В. Устранение неопределенностей при решении задач воздействия на призабойную зону скважин // Известия Томского политехнического университета. Инжиниринг георесурсов. - 2017. - Т. 328, № 7. - С. 40-50.

21. Попльгин В.В. Анализ результатов проведения кислотных обработок в сложных геолого-технологических условиях / В.В. Поплыгин, Е.А. Белоглазова, А.С. Иванова // Вестник Пермского национального исследовательского политехнического университета. Геология. Нефтегазовое и горное дело. - 2014. Tом 13, № 10. - С. 83-90.

22. К вопросу выбора технологии кислотного воздействия для интенсификации добычи нефти / Ю.В. Зейгман, А.В. Лысенков, В.В. Мухаметшин, Ш.Х. Султанов, Ю.А. Котенёв // Геология, геофизика и разработка нефтяных и газовых месторождений. - 2017. - № 6. - С. 44-50.

23. Совершенствование методов оценки и планирования геолого-технических мероприятий на базе статистических данных / В.С. Никитин, С.Д. Глебов, Д.К. Сагитов, А.А. Махмутов // Нефтепромысловое дело. - 2014. - № 12. С. 26-29.

24. Пат. 2117145 Российская Федерация, МПК Е 21 В 43/25. Способ обработки призабойной зоны добывающей скважины / Э.И. Сулейманов, Г.Г. Ганиев, А.И. Иванов, М.Х. Валеев, А.А. Сивухин; заявитель и патентообладатель НГДУ «Бавлынефть» ОАО «Татнефть». № 98103573/03; заявл. 27.02.98; опубл. 10.08.98. Бюл. № 22.4 c.

25. Технология комплексного воздействия на призабойную зону пласта - приоритетное направление развития методов стимуляции сложнопостроенных карбонатных коллекторов в НГДУ «Бавлынефть» / Р.Г. Ханнанов, Р.М. Шакиров, А.А. Сивухин, О.А. Грезина // Георесурсы. - 2006. - № 3. - С. 15-17.

26. Грезина O.A. Критерии оценки результатов кислотно-имплозионного воздействия в нефтяных скважинах // Сборник трудов Международной научнотехнической конференции «Современные технологии в нефтегазовом деле 2015»: в 2-х т. - Уфа: Аркаим, 2015. - Том 1. - С. 73-78.

27. Особенности эксплуатации горизонтальных скважин в НГДу «Бавлынефть» / А.И. Иванов, Р.Г. Ханнанов, О.З. Исмагилов, О.А. Грезина // Материалы се- 
минара-дискуссии «Горизонтальные скважины: бурение, эксплуатация, исследование». - Актюба - Казань: Мастер Лайн, 2000. - С. 48-54.

28. Анализ возможностей оценки потенциальных дебитов горизонтальных скважин на основе моделирования притока с использованием геолого-геофизической информации / Л.Е. Кнеллер, Я.С. Гайфуллин, К.В. Антонов и др. // Материалы семинара-дискуссии «Горизонтальные скважины: бурение, эксплуатация, исследование» . - Актюба - Казань: Мастер Лайн, 2000. - С. 172-180.

29. Гайфуллин Я.С. К оценке влияния особенностей геологического разреза на потенциальные дебиты горизонтальной скважины / Я.С. Гайфуллин, Л.Е. Кнеллер, О.А. Грезина // Геология, геофизика и разработка нефтяных и газовых месторождений. - 2000. - № 9. - С. 29-35.

30. Пат. 2117151 Российская Федерация, МПК Е 21 В 43/25. Способ обработки призабойной зоны добывающей скважины / Н.Г. Ибрагимов, М.М. Залятов, А.Г. Аленькин, М.Х. Валеев; заявитель и патентообладатель ОАО «Татнефть» им. В.Д. Шашина. № 2013143187/03; заявл. 24.09.13; опубл. 27.08.14. Бюл. № 24.5 c.

\section{УВАЖАЕМЫЕ КОЛЛЕГИ!}

ПРИ ИСПОЛЬЗОВАНИИ МАТЕРИАЛА ДАННОЙ СТАТЬИ

ПРОСИМ ДЕЛАТЬ БИБЛИОГРАФИЧЕСКУЮ ССЫЛКУ НА НЕЕ:

Грезина О.А. Оценка эффективности использования наноматериалов при проведении воздействия на призабойную зону скважин после завершения их строительства // Нанотехнологии в строительстве. - 2017. - Том 9, № 6. - С. 6586. - DOI: dx.doi.org/10.15828/2075-8545-2017-9-6-65-86.

\section{DeAr COLLEAGUES!}

THE REFERENCE TO THIS PAPER HAS THE FOLLOWING CITATION FORMAT:

Grezina O.A. Efficiency evaluation for nanomaterials applied in well bottom zone treatment after completion of well construction. Nanotehnologii v stroitel'stve = Nanotechnologies in Construction. 2017, Vol. 9, no. 6, pp. 65-86. DOI: dx.doi. org/10.15828/2075-8545-2017-9-6-65-86. (In Russian). 